$4 \times 7$ in. containers was exchanged with a similar container housing the odor of a novel male. The container housing the novel odor was placed in the female's cage according to a counterbalancing procedure that ensured that the test odors were presented an equal number of times on both sides of the cage. Since two females in different cages were observed at a time, only two odorant males were needed per pair of Ss. Thus, each male could serve as original odorant in one cage and novel odorant in another.

The novel odor was introduced by switching only the $4 \times 7$ in. container. In the first 10 -min period, as a result of her coming in contact with the odorant tubes while investigating the odors within, the female left her own odor on the atrium and removable sleeve. In order to ensure that the only novel stimulus introduced in the second exploratory period was the novel male's odor, the original atrium and sleeve were attached to the new $4 \times 7$ in. container that had earlier housed the novel male. Thus, when the female was placed into her home cage for the second exploratory period, E recorded the amount of time each $S$ spent investigating the novel and original male odors. RESULTS

Table 1 shows the performance of the female Ss during the 10 -min habituation and novelty exploratory periods. The mean difference score (mean time spent investigating the container on the left of the cage minus the mean time spent investigating the container on the right of the cage) of $-0.12 \mathrm{sec}$ after $10 \mathrm{~min}$ of habituation, indicates that the females exhibited no significant tendency to spend more investigation time with either of the odorant tubes when they housed the odors from the same male.

Since the novelty period was the more crucial, the data from this test were recorded in such a manner as to allow an examination of the females' responses after the first and second $10 \mathrm{~min}$ of testing. The mean difference score (mean time spent investigating the novel male odor minus the mean time spent investigating the original male odor) of $+5.12 \mathrm{sec}$ for the first $5 \mathrm{~min}$ of testing reflects the fact that the females spent a significantly greater amount of their investigation time with the novel male odor. (Wilcoxon matched-pairs, signed-ranks test, $\mathrm{T}=20, \mathrm{~N}=15, \mathrm{p}<.02$.) The mean difference score $(+3.90)$ for the second $5 \mathrm{~min}$ of testing was not significantly different from zero. However, when the mean difference scores were computed for the entire $10 \mathrm{~min}$ of testing, the resultant score of $+9.02 \mathrm{sec}$ revealed that the females spent a significantly greater amount of the total investigation time with the novel males odor $(T=17$, $\mathrm{N}=16, \mathrm{p}<.01$ ).

The females' preference for the novel males odor during the novelty period can also be seen by use of the preference ratio index, which shows the number of females that spent the greater portion of their investigation time with the novel male odor divided by the number of females that spent the greater portion with the original male odor ( $\mathrm{Ss}$ that divided their investigation time equally between the two odors were not included in this index). The preference ratio index for the first $5 \mathrm{~min}$ of testing was $12 / 3$; for the second $5 \mathrm{~min}$ of testing it was $11 / 3$; and after the total $10 \mathrm{~min}$ of testing it was $14 / 2$.

The females' response to the novel males' odor in the present study indicates that they are capable of discriminating between males on the basis of bodily odors peculiar to the individual male. The females' prefer the odor of a novel male to an original male prior to copulation but, once copulation ensues, i.e., after one ejaculation or after cessation, she no longer responds preferentially (Carr et al, 1970). This would indicate, as Beach (1965, p. 554) has suggested, that there is a difference in the liability of the male and female to the effects of stimulus satiation and to the effects of novelty upon their sexual behavior.

\section{REFERENCES}

BEACH, F. A. Retrospect and prospect. In F. A. Beach (Ed.), Sex and behavior. New York: Wiley, 1965. Pp. 535-569.

BERLYNE, D. E. Novelty and curiosity as determinants of exploratory behavior. British Journal of Psychology, 1950, 41, 68-80.

BERLYNE, D. E., \& SLATER, J. Perceptral curiosity, exploratory behavior, and maze learning. Journal of Comparative \& Physiological Psychology, 1957, 50, 228-232.

CARR, W. J., KRAMES, L., \& COSTANZO, D. J. Previous sexual experience and olfactory preference for novel versus original sex partners in rats. Journal of Comparative \& Physiological Psychology, 1970, 71, 216-222.

CARR, W. J., LOEB, L. S., \& DISSENGER, M. L. Responses of rats to sex odors. Journal of Comparative \& Physiological Psychology, 1965, 59, 370-377.

COURTNEY, C. C., REID, L. D., \& WASDEN, R. Suppression of running times by olfactory stimuli. Psychonomic Science, 1968, 12, 315-316.

KRAMES, L. The Coolidge effect in male and female rats. Unpublished doctoral dissertation, Temple University, 1969.

MONTGOMERY, K. C. Exploratory behavior as a function of "similarity" of stimulus situations. Joumal of Comparative \& Physiological Psychology, 1953, 46, 129-133. ZUCKER, I., \& WADE, C. Sexual preferences of male rats. Journal of Comparative \& Physiological Psychology, 1968, 66, 816-819.

\title{
The effect of changes in ambient temperature on water intake and evaporative water loss*
}

\author{
PHILIP BUDGELL \\ Institute of Experimental Psychology, Oxford, England
}

Rats deprived of water at the same temperature and tested at different temperatures drink different amounts. The conclusion that ambient temperature has a direct effect on drinking is supported by the finding that evaporative water loss at the different temperatures could not account for the differential water intake.

In many species there is a positive correlation between water intake and ambient temperature. Three hypotheses have been proposed to explain this relationship: (1) Drinking may be stimulated by local dryness of the oral pharyngeal membranes caused by water evaporation at high environmental temperatures (Gregerson \& Cannon, 1932). (2) Drinking may be stimulated by

*This research was supported by a grant from the Science Research Council. The author wishes to thank J. Ienton for his assistance in carrying out the experiments. systemic dehydration consequent upon thermoregulatory water loss (Hainsworth, Striker, \& Epstein, 1968). (3) Drinking may be altered by deviations from the normal brain temperature (Andersson, 1963).

The second hypothesis has received considerable attention from Hainsworth and his co-workers. Rats neither sweat nor pant during heat stress, but increase heat loss through the evaporation of saliva spread onto their body surfaces. Hainsworth (1968) indicates that the salivary loss of normal rats at high ambient 


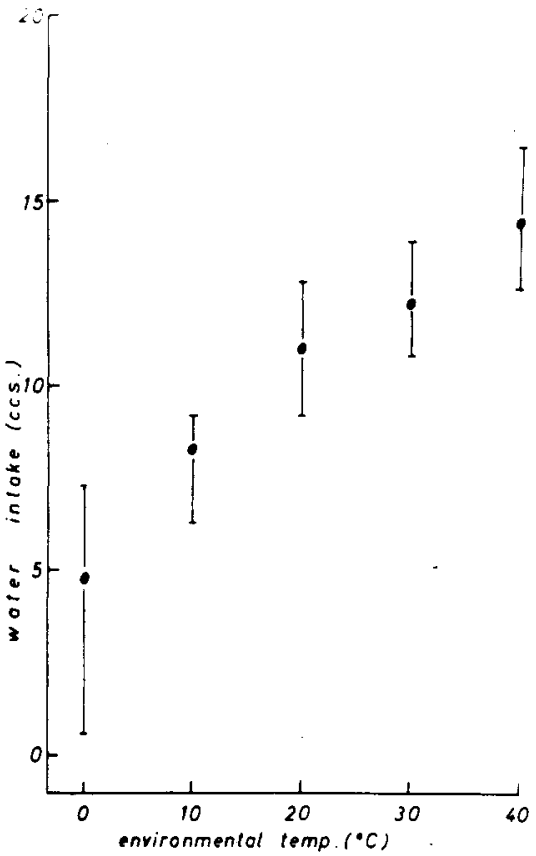

Fig. 1. Water intake during operant drinking tests as a function of ambient temperature. Vertical lines indicate range. Kruskal-Wallis, $\mathbf{H}=25.9, \mathrm{p}<0.001$.

temperature is considerable and can lead to severe dehydration. Hainsworth, Striker, \& Epstein (1968) demonstrate that nondeprived animals subjected to $40^{\circ} \mathrm{C}$ heat stress did not commence drinking until 2-3 $\mathrm{h}$ after the onset of hyperthermia and only after dehydration had become severe. They also demonstrate that the water ingested by the rats was just sufficient to make up for the evaporative water loss. They conclude, "The contribution of hypothermia to drinking in rats in the heat seems doubtful ... the primary stimulus for drinking during heat stress seems to be the degree of dehydration."

Recent work by Budgell (1970) shows that in the Barbary dove (Streptopelia risoria) both normal and operant drinking are influenced by the ambient temperature at which the drinking test is conducted. Such drinking can be regarded as a modulation of the normal $\left(20^{\circ} \mathrm{C}\right)$ drinking response, so that the animals "under-drink" at low temperature and "over-drink" at high temperatures. The experiments reported here involve an adaptation of Budgell's method.

\section{EXPERIMENT}

Method

Six adult female albino rats (weighing $225-250 \mathrm{~g}$ ) were housed at $20^{\circ} \mathrm{C}$ on an $8 \cdot \mathrm{h}$ light/16-h dark cycle. The six $\mathrm{Ss}$ were trained daily for 2 weeks to obtain $0.1 \mathrm{~cm}^{3}$ water rewards by barpressing in a Skinner box maintained at $20^{\circ} \mathrm{C}$ in a climatic cabinet. During the experimental period the Ss were tested every third day in the Skinner box following $24 \mathrm{~h}$ of water deprivation, and were run to a satiation criterion of $5 \mathrm{~min}$ without responding. Water was available in the home cages for $48 \mathrm{~h}$ subsequent to testing. The testing procedure consisted in placing the animal in the Skinner box for a 30-min acclimatization period before water was made available. The animals were tested at $20^{\circ}, 10^{\circ}, 30^{\circ}, 0^{\circ}$, and $40^{\circ} \mathrm{C}$, in that order. $A$ record was kept of the number of rewards obtained during each test.

\section{Results}

The results are summarized in Fig. 1. These show a significant increase in the amount drunk as a function of increasing ambient temperature (Kruskal-Wallis $\mathbf{H}=25.9, \mathrm{p}<.001)$. This finding suggests that water intake can change as a direct response to ambient temperature.

\section{EXPERIMENT 2}

Hainsworth et al (1968) suggest that drinking can only occur in response to dehydration resulting from saliva spreading. This experiment was performed to see if the animals in the previous experiment did lose water during the acclimatization period before responding.

\section{Methods}

The Ss were the six female albino rats used in the previous experiment. They were again housed at $20^{\circ} \mathrm{C}$ on an $8-\mathrm{h}$ light/16-h dark cycle. The Ss were kept on an ad lib regime and tested every 3 days. The test procedure merely involved being placed in the climatic cabinet for $1 \mathrm{~h}$, each $\mathrm{S}$ being weighed before and after testing. The Ss were tested at $20^{\circ}, 10^{\circ}, 30^{\circ}, 0^{\circ}$, and $40^{\circ} \mathrm{C}$, in that order. The whole experiment was then repeated with the animals deprived of water for $24 \mathrm{~h}$ prior to testing.

\section{Results}

The findings are summarized in Table 1. The results for the ad lib conditions are in agreement with Hainsworth and his

Table 1

Weight Loss During 1-H Test Period at Various Ambient Temperatures

\begin{tabular}{lllllr}
\hline Ambient Temperature & $0^{\circ} \mathrm{C}$ & $10^{\circ} \mathrm{C}$ & $20^{\circ} \mathrm{C}$ & $30^{\circ} \mathrm{C}$ & $40^{\circ} \mathrm{C}$ \\
\hline Ad Lib & $0.0 \mathrm{~g}$ & $0.0 \mathrm{~g}$ & $0.0 \mathrm{~g}$ & $0.42 \mathrm{~g}$ & $3.5 \mathrm{~g}$ \\
24-H Water Deprivation & $0.0 \mathrm{~g}$ & $0.0 \mathrm{~g}$ & $0.0 \mathrm{~g}$ & $0.0 \mathrm{~g}$ & $0.43 \mathrm{~g}$ \\
t test & n.s. & n.s. & n.s. & n.s. & p 0.01 \\
\hline
\end{tabular}

co-workers. At $40^{\circ} \mathrm{C}$ the rats spread saliva over the body surface and the evaporation of this saliva gave rise to the weight loss. Under deprivation conditions, however, the weight loss at $40^{\circ} \mathrm{C}$ was significantly lower, the majority of the loss coming from one rat, this rat being the only one observed to spread saliva. It appears that rats already subject to a water debt are unwilling to use evaporative water loss as a mechanism of heat loss.

\section{DISCUSSION}

The results of the experiments reported in this paper indicate that operant drinking can be influenced by the temperature at which the drinking-test is conducted. Furthermore, the results indicate that the increase in water intake at temperatures up to $30^{\circ} \mathrm{C}$ is not due to water loss, as Hainsworth et al (1968) suggest. Moreover, at $40^{\circ} \mathrm{C}$, the only temperature at which deprived animals lost any weight, the mean water loss was $0.43 \mathrm{~cm}^{3}$, whereas the mean increase in water intake $\left(40^{\circ} \mathrm{C}\right.$ compared with $20^{\circ} \mathrm{C}$ ) was $3.9 \mathrm{~cm}^{3}$. The only rat observed to spread saliva at $40^{\circ} \mathrm{C}$, when deprived, lost $2.3 \mathrm{~g}$ of water; this same animal drank $2.42 \mathrm{~g}$ more water at $40^{\circ} \mathrm{C}$ than the mean intake of the other five rats, but drank no more at the other temperatures.

Despite the elegant way in which Hainsworth et al (1968) demonstrate that the positive correlation between water intake and ambient temperature can be caused by systemic dehydration, their experiments did not allow for the separation of environmental temperature and systemic dehydration. The experiments reported here lend support to the hypothesis that drinking may be altered by changes in environmental temperature. The physiology of these changes remains an open question, but it is possible that they are mediated by changes in hypothalamic temperature (Anderson, 1963).

\section{REFERENCES}

ANDERSON, B. Aspects of the interrelations between central body temperature and food and water intake. In M. Brazier (Ed.), Brain and behavior. II. Washington, D.C: American Institute of Biological Sciences, 1963.

BUDGELL, P. Modulation of drinking by ambient temperature changes. Animal Behaviour, 1970 , in press.

GREGERSON, M. I., \& CANNON, W. B. Studies on the regulation of water in take. I. The effect of extirpation of the salivary glands on the water intake of dogs while panting. American Journal of Physiology, 1932, 102, 336-343.

HAINSWORTH, F. R. Evaporative water loss from rats in the heat. American Journal of Physiology, 1968, 214, 979-982.

HAINSWORTH, F. R., STRIKER, E. M., \& EPSTEIN, A. N. Water metabolism in the heat: Dehydration and drinking. American Journal of Physiology, 1968, 214, 983-989. 